Razafindratsima, Onja H., Brown, Kerry A., Carvalho, Fabio, Johnson, Steig E., Wright, Patricia C. and Dunham, Amy E. (2018) Edge effects on components of diversity and above-ground biomass in a tropical rainforest. Journal Of Applied Ecology, 55(249), pp. 977-985. , which has been published in final form at https:// doi.org/10.1111/1365-2664.12985. This article may be used for non-commercial purposes in accordance with Wiley Terms and Conditions for Self-Archiving. 


\author{
Article type : Research Article \\ Editor : Nathalie Butt
}

\title{
Edge effects on components of diversity and above-ground biomass in a tropical
} rainforest

Onja H. Razafindratsima ${ }^{1}$, Kerry A. Brown ${ }^{2}$, Fabio Carvalho ${ }^{2}$, Steig E. Johnson ${ }^{3,4}$, Patricia C. Wright $^{5,4}$ and Amy E. Dunham ${ }^{6,4}$

${ }^{1}$ Department of Organismic and Evolutionary Biology, Harvard University, 26 Oxford St., Cambridge, Massachusetts 02138, USA

${ }^{2}$ Department of Geography and Geology, Kingston University, Penrhyn Road, Kingston Upon Thames, Surrey KT1 2EE, UK

${ }^{3}$ Department of Anthropology and Archaeology, University of Calgary, 2500 University Drive NW, Calgary Alberta, T2N 1N4, Canada

${ }^{4}$ Centre ValBio, BP 33 Ranomafana, Ifanadiana Fianarantsoa, Madagascar

${ }^{5}$ Department of Anthropology, Stony Brook University, Circle Rd, SBS Building S-501, Stony Brook, NY 11794-4364, USA

${ }^{6}$ Department of BioSciences, Rice University, 6100 Main Street, Houston, Texas 77005, USA

This article has been accepted for publication and undergone full peer review but has not been through the copyediting, typesetting, pagination and proofreading process, which may lead to differences between this version and the Version of Record. Please cite this article as doi: 10.1111/1365-2664.12985

This article is protected by copyright. All rights reserved. 


\section{Corresponding author}

Onja H. Razafindratsima

22 Divinity Avenue, Cambridge, Massachusetts 02138, USA

Email: onja@ ricealumni.net

\section{ABSTRACT}

1. Edge effects are among the most significant consequences of forest fragmentation.

Therefore understanding the impacts of edge creation on biodiversity is crucial for forest management and biological conservation.

2. In this study, we used trait-based and phylogenetic approaches to examine the effects of fragmentation on components of diversity and above-ground biomass of rainforest tree communities in Madagascar in forest edge vs. interior habitats.

3. Tree communities in forest edges showed lower phylogenetic diversity relative to those in interior habitats, suggesting that some clades may be more vulnerable to environmental filtering than others. Functional diversity was also significantly lower on the edge for productivity traits, but not for dispersal traits. Tree communities in the forest edge showed higher divergence of dispersal traits and lower divergence in productivity traits than expected, while functional diversity in interior forest did not differ from random expectations. This suggests separate mechanisms affect productivity traits $v s$. dispersal traits in edge habitats.

4. There was no significant difference in above-ground biomass between edge and interior habitats, suggesting that edge effects have not yet negatively influenced the forest's potential for carbon storage. However, these changes may not have occurred yet, given the slow turnover of tree communities.

5. Synthesis and applications. Our results highlight the role of edge effects in the erosion of

This article is protected by copyright. All rights reserved. 
functional and phylogenetic diversity of highly diverse tree communities. While aboveground biomass did not appear to be affected by forest edge in our study, we suggest long-term monitoring of forests for potential changes in ecosystem functioning. These findings also indicate the need to reduce edge creation and buffer existing edges for holistic biodiversity conservation.

Keywords: carbon storage, environmental filtering, functional diversity, biomass, phylogenetic diversity, seed dispersal, species coexistence, tropical forest, forest fragmentation

\section{INTRODUCTION}

Globally, forest ecosystems are becoming increasingly fragmented, such that $70 \%$ of the world's forest area is currently within $1 \mathrm{~km}$ of the forest edge (Haddad et al. 2015). The artificial boundaries created during forest fragmentation can have diverse impacts on forest edges (edge effects), including changes in local species composition, diversity and ecological functioning (Murcia 1995; Haddad et al. 2015). However, little is known about how edge creation may also alter phylogenetic or functional components of biodiversity and linkages to ecosystem function, such as the forest's potential for above-ground carbon storage (but see Chaplin-Kramer et al. 2015; Magnago et al. 2017). Characterizing the potential consequences of forest-edge creation on the diversity and functioning of forest ecosystems is important for resource management and conservation.

Plants display a range of functional traits that may influence their ability to persist and colonize in altered habitats (Cornelissen et al. 2003; Marini et al. 2012; Asanok et al. 2013). Two main categories of plant functional traits that may be especially crucial for plant fitness are dispersal and productivity traits. Traits associated with a plant's dispersal ability, such as

This article is protected by copyright. All rights reserved. 
fruit/seed traits and dispersal mode (e.g., mammal-, bird- or wind-dispersed), may influence rates of recruitment and colonization (Schupp 1995; Nathan \& Muller-Landau 2000), whereas traits related to productivity (e.g., leaf area and wood density) may be important for competition and tolerance to certain environmental conditions (Ding et al. 2012; Lasky et al. 2013). Characterizing the diversity of these functional traits in edge $v s$. interior habitats can provide important insights about edge effects on tree communities and for understanding mechanisms driving patterns of community structure in fragmented landscapes (Marini et al. 2012; Asanok et al. 2013). This is especially critical in the face of current anthropogenic pressures, which have begun to alter patterns of species composition within communities (Avise, Hubbell \& Ayala 2008; Razafindratsima, Mehtani \& Dunham 2013).

Species traits are often shared by closely related species; thus, phylogenetic relationships within a community are often used as proxies for trait similarities in understanding community diversity (Cavender-Bares et al. 2009; Gerhold et al. 2015). This approach may have advantages by representing unmeasured or complex traits better than a limited number of measured traits (Helmus et al. 2007; Cavender-Bares et al. 2009). However, phylogenetic patterns used as proxy for trait diversity can be misleading if trait differences display patterns of convergence or divergence on the phylogeny (i.e., when trait differences and phylogenetic distances are not proportional). Therefore, combining traitbased analyses with phylogenetic information can provide complementary information and allows more comprehensive insights into community diversity patterns.

More extreme environmental conditions could favour closely related species sharing certain traits that allow them to tolerate such conditions (environmental filtering) (Webb et al. 2002; Mayfield \& Levine 2010). In forest edge habitats, environmental conditions may result in the prevalence of tree species with similar dispersal mode or fruit/seed traits that allow them to establish in more exposed areas. Edges may also result in the clustering of traits

This article is protected by copyright. All rights reserved. 
related to species' tolerance and competitive abilities in high light conditions (Westoby et al. 2002; Mayfield \& Levine 2010). Alternatively, edge habitat may function as transition habitat between interior forest and surrounding habitat, such that species with dispersal or productivity traits that are rare or absent in the interior forests may be more common on the edge, leading to higher functional and phylogenetic diversity in the edge community (Grime 2006).

Given that functional and phylogenetic diversity among species in a community often drive biodiversity-ecosystem-function relationships (Díaz \& Cabido 2001; Flynn et al. 2011; Zhu, Jiang \& Zhang 2016), changes in these metrics resulting from edge disturbance may have implications for carbon storage in above-ground tree biomass. For example, tree communities dominated by distantly related species can yield greater biomass production because of their functional distinctness and low niche overlap (Cadotte, Cardinale \& Oakley 2008; Cadotte et al. 2009). A recent pantropical study using remote sensing suggested large negative effects of edge habitat on carbon storage in forests (Chaplin-Kramer et al. 2015). However, at such large scales, it is difficult to separate human encroachment, common in edge forest, from actual edge effects. Local-scale studies of edge effects on forest carbon storage are limited but allow for greater precision and resolution of these effects as well as insight about potential mechanisms (Magnago et al. 2017) and linkages with changes in biodiversity components.

There are several mechanisms by which edges may affect diversity components and carbon storage of tree communities. For example, some studies have suggested that trees relying on large-bodied fauna for seed dispersal commonly have higher above-ground biomass (Poulsen, Clark \& Palmer 2013; Peres et al. 2016; Osuri et al. 2016). Thus, if plant species dispersed by large-bodied fauna are less abundant in forest edges, there could be altered functional trait diversity and reduced carbon storage (Osuri et al. 2016; Osuri \&

This article is protected by copyright. All rights reserved. 
Sankaran 2016). Also, productivity traits and above-ground biomass may differ in forest edges because of the replacement of old-growth species by low-density pioneer species that thrive in open high-light habitats in the edge (Laurance et al. 2006a; b).

In this study, we used vegetation surveys from the south-eastern rainforest of Madagascar to explore the potential linkages between diversity components and aboveground biomass in edge and intact habitats. We tested the hypothesis that edge effects would include altered phylogenetic and functional diversity (dispersal and productivity traits) of tree communities. We also examined whether differences in trait distributions between interior and edge communities would be associated with lower above-ground biomass.

\section{MATERIALS AND METHODS}

\section{Study site and vegetation sampling}

This study was conducted in the evergreen montane rainforests of Ranomafana National Park (RNP) in south-eastern Madagascar (47 $\left.18^{\prime}-47^{\circ} 37^{\prime} \mathrm{E}, 21^{\circ} 02^{\prime}-21^{\circ} 25^{\prime} \mathrm{S}\right)$. RNP comprises an area of 41,600 ha with an elevation of 600-1500 m (Wright \& Andriamihaja 2002), and is home to more than 330 species of trees and large shrubs (Razafindratsima \& Dunham 2015), most of which rely on a limited set of frugivores for dispersal (Razafindratsima \& Dunham 2016a). The climate in Ranomafana is highly seasonal with average monthly rainfall ranging from 10-1200 mm, an average annual rainfall of $2830 \mathrm{~mm}$, a peak wet season in Jan-Mar and a peak dry season in Jun-Oct (Dunham, Erhart \& Wright 2011). Fruiting in RNP occurs yearround, with a peak in the abundance of trees fruiting in April (Razafindratsima \& Dunham 2016a).

Vegetation surveys were undertaken in seven sites within RNP (Supporting Information Fig. S1) from Oct 2003 - June 2005 (Brown et al. 2011). In each site, a 40 x 40 $\mathrm{m}$ plot was established in forest edge habitat (with the centre of the plot at $20 \mathrm{~m}$ from forest

This article is protected by copyright. All rights reserved. 
edge toward the interior) and another in interior habitat (with the centre of the plot located at least $500 \mathrm{~m}$ and up to 3,220 $\mathrm{m}$ from the edge). Forest boundaries were characterized by hard edges, with little or no successional gradient between forest and non-forest. The non-forest matrix adjoining edge plots consisted primarily of habitats associated with small-scale agriculture, including active, fallow and abandoned fields. This habitat transition has existed for $>26$ years since the park was founded in 1991. During its establishment, the park boundaries generally followed the contours of remaining forest with variable extent of forest buffer outside the limits (Supporting Information Fig. S1). The edge-forest habitat at RNP has been used at relatively low intensity for obtaining forest products such as dead wood for fuel. The landscape matrix in Ranomafana is representative of forested environments in eastern Madagascar, which extend along the eastern escarpment from northern to southern Madagascar (inset in Supporting Information Fig. S1).

Within each plot, we recorded the species identity, diameter at $1.3 \mathrm{~m}$ height (dbh) and height of all woody stems with $>10 \mathrm{~cm}$ dbh. Species in our plots were identified according to local research technicians trained in floristic identification. We also used the databases Tropicos (http://www.tropicos.org/) and The Plant List (http://www.theplantlist.org/), as well as the detailed floral descriptions in Schatz (2001) and Turk (1995). We checked the accuracy of our species names using the Taxonomic Name Resolution Service v4.0 (http://tnrs.iplantcollaborative.org/). In total, we recorded 157 tree species, 90 genera and 43 families in all plots (with 122 species recorded in forest edges and 129 species in interior habitats), for a total of 2066 individuals. Communities in each plot were composed of 21-51 species (with an average of $956 \pm 66.02$ individual trees per ha).

This article is protected by copyright. All rights reserved. 


\section{Species richness and composition}

For each tree community in each plot, we calculated species richness $(S)$ and a diversity index using an exponential of the value of Shannon entropy index that represents "effective number of species" (expH) (Hill 1973; Jost 2006). We also examined differences in community composition between habitat types using nonmetric multidimensional scaling (NMDS) ordination (Benítez-Malvido et al. 2014) and PERMANOVA analysis (see Appendix S1).

\section{Phylogenetic diversity}

We used the web-based service Phylomatic v3 (Webb \& Donoghue 2005) to build a regional phylogenetic tree (Appendix S2) that contained all known woody trees/shrubs in RNP. The list of known tree/shrub species in RNP was generated from our vegetation sampling from this study in addition to data from Centre ValBio's long-term research program (Wright unpubl. data), and OHR's previous inventory of plant species in Ranomafana (Razafindratsima, Jones \& Dunham 2014; Razafindratsima \& Dunham 2015, 2016a; b; Razafindratsima unpbl. data). Species names were checked for accuracy and synonyms using the methods described above in our vegetation sampling methods. Phylomatic takes the taxa in our list (with family and genus) to match with the most resolved position possible in a user-specified megatree. In this study, we used the megatree "zanne2014", a phylogenetic tree of angiosperms with calibrated branch lengths developed by Zanne et al. (2014).

We characterized the phylogenetic diversity of each community in forest edge and interior habitats by measuring a Mean pairwise Phylogenetic Distance $(M P D)$ and compared it with null communities by estimating the Net Relatedness Index (NRI) (Webb 2000). MPD measures the average evolutionary distance between all pairwise species in a community; a higher value of $M P D$ means that the members of the community are less related to each other than the members of the community with a lower value. NRI is estimated as follows:

This article is protected by copyright. All rights reserved. 


$$
N R I=-1 \frac{M P D_{o b s}-M P D_{\text {null }}}{s d\left(M P D_{\text {null }}\right)}
$$

Values of $N R I$ indicate whether taxa in a community are phylogenetically clustered (higher relatedness; positive values) or overdispersed (species are phylogenetically less related; negative values) relative to random expectations. Calculations of $N R I$ values for each community were performed with functions in the picante package (Kembel et al. 2010) in $\mathrm{R}$ (R Core Team 2016).

Null communities were generated from random draws of species from a pool of all tree species in the regional phylogeny, maintaining the species richness within each community (9999 permutations, phylogeny.pool in R). Given that several different randomization models can be used to calculate NRI (Webb et al. 2002), we initially tested the effects of model selection by testing the correlation of $N R I$ values from four different models ("phylogeny.pool”, "richness", "frequency" and "independentswap"), using Pearson correlation tests. Correlation coefficients between the models were very high $(R=0.96-$ 0.99). We performed one-sample $t$-tests to examine the deviation of $N R I$ values from random expectations (zero) for communities in each habitat type (Razafindratsima, Mehtani \& Dunham 2013; Sydenham et al. 2015). To assess whether the phylogenetic diversity metric $M P D$ differed between tree communities in forest edge and interior habitats, we performed linear mixed-effects models (normal distributions), with the nlme package in R; the variable habitat type (edge $v s$. interior) was treated as a fixed effect and transect locations (sites) treated as a random effect.

\section{Trait dataset and functional diversity}

We used traits that measured dispersal and productivity (Table 1) of each tree species identified in our plots. The sampling methods and measurements for each trait variable are detailed in Appendix S3 and a list of data sources for traits collected from the literature and

This article is protected by copyright. All rights reserved. 
public databases are provided in the Data Sources section. We gathered trait data for more than $72 \%$ of the species in our plots and we obtained $>90 \%$ of the trait data for 8 out of the 10 most abundant species.

Analyses of phylogenetic signal in each of these trait variables (i.e., tendency of related species to resemble each other), using Pagel's lambda (Pagel 1999), show that fruit length and seed size category display significant phylogenetic signal, while there was a nonsignificant phylogenetic signal in seed dispersal mode and fruit colour categories and no signal in fruit width (Appendix S4). Productivity traits display significant phylogenetic signals in leaf area, wood density and longevity, and non-significant signals in average height, spinescence and growth rate (Appendix S4).

We characterized the functional diversity of each tree community, in terms of dispersal- and productivity-related traits, by measuring Petchey and Gaston's Functional Diversity index, $F D$ (Petchey \& Gaston 2002). FD is a dendrogram-based metric that estimates the dispersal of a community of species in trait space and automatically accounts for covariance between traits. Communities with high divergence in trait space are expected to yield higher $F D$ values than communities with low trait divergence. We used algorithms in $\mathrm{R}$ (R Core Team 2016) to calculate $F D$. Continuous trait variables were standardized to have a mean of zero with a unit standard deviation. We used the Gower standardization method to calculate the multivariate distances between species required to compute this metric. Species with any missing trait values were excluded from the calculations. In total, 108 species were used for the functional analyses of dispersal traits and 139 species for productivity traits.

To evaluate how the values of functional diversity are distributed within the communities, we compared the observed values of $F D\left(F D_{o b s}\right)$ to that of null expectations $\left(F D_{\text {null }}\right)$, by calculating an Index of Variance (IV) as follows (Mason et al. 2008):

$$
I V . F D=2\left(\frac{F D_{\text {obs }}}{F D_{\text {obs }}+F D_{\text {null }}}\right)-1
$$

This article is protected by copyright. All rights reserved. 
$I V$ gives a stable index of the ratio between observed and expected values and standardizes values between -1 and 1 ; a positive value of $I V$ indicates that the observed value is greater than the value expected at random, indicating trait divergence (Mason et al. 2008). Null expectations were estimated from 9999 randomly generated communities, using the "richness" option implemented in the package picante in $\mathrm{R}$ (in which abundances within communities were randomized but the species richness in each community was maintained). We included species from all sampled plots in the pool for null communities, rather than those in nearby paired plots only, because the dispersal of these species is not restricted to the sites and these plant species could be potential colonists of each plot. Including all species in the pool - similar to the randomization for phylogenetic analyses - was not possible because we did not have trait data for all species in the region to create a trait dendrogram. We used one-sample t-tests to determine whether the mean of the distribution across communities for $I V . F D$ significantly deviated from random expectations (hypothesized mean $=0$ ). Similar to the analyses with phylogenetic diversity above, we also assessed whether the functional diversity metric $F D$ differed between communities in forest edge and interior habitats using linear mixed-effects models.

\section{Above-ground biomass}

We measured total above-ground biomass in each plot by summing the above-ground biomass of each individual tree within each plot and dividing the sum by the total sampled area; the resulting value is converted into $\mathrm{Mg} / \mathrm{ha}$. Estimates of individual-level above-ground biomass were calculated using the following allometric equation developed by Chave et al. (2005) for moist forest stands:

$$
A G B=e^{-2.977+\ln \left(\rho D^{2} H\right)}
$$

$\rho, D$ and $H$ respectively correspond to individual values of wood density (in $\mathrm{g} / \mathrm{cm}^{3}$ ), tree

This article is protected by copyright. All rights reserved. 
diameter at breast height (in $\mathrm{cm}$ ) and tree height (in $\mathrm{m}$ ). We found similar patterns when using other allometric models (Appendix S5); thus, we only present the results of one model in this study. We used linear mixed-effects models as described above to assess whether above-ground biomass differed significantly between tree communities in forest edge and in interior habitats.

\section{RESULTS}

\section{Species richness and composition}

While the difference in mean species richness between communities in edge (36.00 \pm SE 3.49 species per plot) and interior habitats (43.57 \pm SE 1.56 species per plot) was marginally nonsignificant $\left(t_{6}=2.03, P=0.09\right)$, the exponential of Shannon diversity index $(\exp H)$ showed a significantly lower diversity in edge habitats $\left(t_{6}=4.38, P=0.005\right.$; edge mean $=20.57 \pm \mathrm{SE}$ 2.20 ; interior mean $=27.05 \pm \mathrm{SE} 1.45)$. An ordination of edge and interior tree community composition suggested the difference in species composition between these two habitats was non-significant, though only marginally (PERMANOVA, $F_{1,12}=1.240, P=0.06$ ) (Fig. 1).

\section{Phylogenetic species diversity}

The mean value of $M P D$ shows that the species in the edge habitat were significantly more phylogenetically related than those in the interior habitat (Fig. 2A; mean MPD in edge: $242.01 \pm 9.07 \mathrm{MY}$, interior: $266.58 \pm 5.99 \mathrm{MY})$. Mean NRI indicates that the communities in edge habitats were composed of species that were neither more nor less related than expected by chance (mean $N R I=-0.09 ; t_{6}=-0.35, P=0.73$ ), and significant phylogenetic dispersion (i.e. composed of species that are more distantly related than expected by random assembly) for communities in interior habitats (mean $N R I=-0.93 ; t_{6}=-3.16, P=0.02$ ). However, the difference in mean values of $N R I$ between these two habitat types was only marginally

This article is protected by copyright. All rights reserved. 
significant $\left(t_{6}=-2.45, P=0.05\right)$.

\section{Functional diversity}

The mean value of $F D$ of dispersal traits was not significantly different between tree communities in edge and interior habitats (Fig. 2B). Compared with null expectations, the observed $F D$ of dispersal traits for tree communities near forest edge was significantly higher than expected by chance (Fig. 3A; mean $I V . F D=0.05 \pm 0.02, t_{6}=2.72, P=0.03$ ). However, for the communities in interior habitats, observed $F D$ of dispersal traits did not differ from random expectations (Fig. 3A; mean $I V . F D=0.02 \pm 0.01, t_{6}=1.39, P=0.21$ ). For productivity-related traits, $F D$ was significantly lower in forest edge than in interior habitat (Fig. 2C). Compared with null expectations, the $F D$ of productivity traits was significantly lower than random expectation for tree communities near forest edge (Fig. 3B; mean $I V . F D=$ $\left.-0.08 \pm 0.03, t_{6}=-2.86, P=0.03\right)$; it did not differ from random expectations for the communities in interior habitats (Fig. 3B; mean IV.FD $=0.02 \pm 0.02, t_{6}=1.04, P=0.33$ ). Simple linear regression analyses showed that the deviations of $F D$, for either type of traits, from null expectations were not related to species richness (dispersal traits: $R^{2}=0.03, P=$ 0.54; productivity traits: $\left.R^{2}=0.002, P=0.88\right)$.

\section{Above-ground biomass}

We found that total above-ground biomass was not significantly different between the tree communities in forest edge and interior habitats (Fig. 2D; mean in edge $=188.48 \pm 47.14$ $\mathrm{Mg} / \mathrm{ha}$, mean in interior $=242.96 \pm 34.49 \mathrm{Mg} / \mathrm{ha})$.

This article is protected by copyright. All rights reserved. 


\section{DISCUSSION}

In forests worldwide, edge effects are among the most significant consequences of forest fragmentation (Murcia 1995; Haddad et al. 2015). Determining how forest edges impact the diversity of vegetation and ecosystem processes is therefore crucial for forest management and conservation. In a Malagasy rainforest, we found lower phylogenetic diversity in tree communities in the forest edge than in interior habitats, suggesting that some clades may be more vulnerable to edge environments than others (i.e., potential environmental filtering) or have a competitive advantage. This was supported by the lower diversity of productivity traits in edge habitat relative to both interior and to random expectations. Despite these differences in productivity traits, edge effects in this system did not negatively influence above-ground biomass (a proxy for carbon storage), despite $>26$ years since edge creation. The functional diversity measures of dispersal traits did not differ between tree communities in edge and interior habitat. However, dispersal traits in edge habitat were more diverse than expected from random assemblages.

The lower phylogenetic diversity in edge communities found in this study was similar to results found in previous studies of degraded habitats (Santos et al. 2010; Norden et al. 2012; Letcher et al. 2012; Ding et al. 2012). The more extreme environmental conditions of edge and degraded habitats may select for more closely related species sharing traits allowing them to tolerate these conditions (Webb et al. 2002; Santos et al. 2010) and/or to be competitive in such an environment (Mayfield \& Levine 2010; Kunstler et al. 2012). Additionally, the activities of people living on the forest periphery (small-scale agriculture adjacent to the forest and low-intensity harvest of non-timber forest products in the forest near edges) could contribute as a selective force on traits in forest edge communities (Brown et al. 2013).

This article is protected by copyright. All rights reserved. 
The effects of forest edge habitat on functional diversity in our study, however, were not straightforward, but depended on trait type, suggesting that different diversity components may respond differently to disturbance (Giehl \& Jarenkow 2015). The different patterns of diversity of productivity and dispersal traits across habitat types in this system may be explained by the higher number of evolutionarily labile dispersal traits relative to productivity traits (Appendix S4); a pattern that is also found in other systems (Stournaras et al. 2013; Giehl \& Jarenkow 2015). Our functional diversity results also suggest that independent mechanisms may structure the diversity of productivity and dispersal traits (Grime 2006). The lower diversity of productivity traits (reflecting the pattern of phylogenetic diversity) on the forest edge are consistent with previous studies (Van der Plas, Anderson \& Olff 2012), and may result from a filtering effect of the more extreme environmental conditions in the forest edge (Swenson \& Enquist 2009), or increased selection for species with certain traits related to competitive ability in edge habitat. In contrast, the patterns of divergence in dispersal traits may be a result of differences in frugivore communities between edge and interior habitats. Habitat-edge avoidance by largebodied frugivores, which are the primary dispersers for a majority of plants in the system (Razafindratsima \& Dunham 2016a) may create opportunities for some typically rare dispersal strategies to become more prevalent in the community, increasing diversity of dispersal-related traits in edge habitat (Brodie \& Aslan 2012; Kurten, Wright \& Carson 2015).

Despite differences in diversity components between communities in forest edge and interior habitats, community above-ground biomass was found to be similar between these habitat types. This result reflects the similarities between tree communities in edge and interior habitats in forest structure and in distributions of the three traits used to estimate above-ground biomass (Appendix S6 and S7). Similarities in above-ground biomass was

This article is protected by copyright. All rights reserved. 
contrary to our expectations and does not accord with large-scale studies of edge effects on carbon storage (Chaplin-Kramer et al. 2015; Brinck et al. 2017), or studies showing that phylogenetic and functional diversity can be a strong predictor of community productivity (Cadotte, Cardinale \& Oakley 2008; Flynn et al. 2011). It is important to consider, however, that the time scale of edge creation may affect the intensity of edge effects (Magnago et al. 2017). Given the longevity of many tree species, the forest edge may still be facing local extinction debt in this system even after $>26$ years since fragmentation (Laurance et al. 2000).

It is also possible that, in this system, edge habitats have a limited effect on biomass. Our results show that the interior forests of Ranomafana have low above-ground biomass $(243 \pm \mathrm{SE} 91 \mathrm{Mg} / \mathrm{ha})$, relative to African, Asian or Neotropical forests (respectively $418.3 \pm$ 91.8Mg/ha, $393.3 \pm 109.3 \mathrm{Mg} / \mathrm{ha}$ and $287.8 \pm 105.0 \mathrm{Mg} / \mathrm{ha}$; Slik 2005). This may be a result of a system that is frequented by strong cyclone disturbance (Dunham, Erhart \& Wright 2011), which may limit the potential difference in above-ground carbon storage between edge and interior forests. However, the biomass result should be treated with caution because of the low sample size of our study, as well as the longstanding limitation of estimating aboveground biomass from allometric relationships, rather than direct measurements (Lewis et al. 2013). Further work across more systems will help clarify edge effects on above ground forest biomass.

Our results indicate that forest edge creation can reduce diversity beyond species composition and richness, and highlight the need to reduce edge creation and buffer existing edges for biodiversity conservation in forest ecosystems. We suggest that tropical forest management efforts should contribute to phylogenetic and functional diversity of trees while preserving the functioning and resilience of forest ecosystems under future changing environmental conditions. Although above-ground biomass did not appear to be affected by

This article is protected by copyright. All rights reserved. 
forest edge in this system, our results indicate that long-term monitoring of forests is crucial for understanding potential changes in ecosystem functioning.

\section{ACKNOWLEDGMENTS}

Field research and logistical support was provided by Rice University, MICET and Centre ValBio; and through grants to O.H.R. by The Rufford Foundation (No. 5748-2) and Rice University (Centennial Award to Support Undergraduate Research), to P.C.W. by the David and Lucile Packard Foundation, and to S.E.J. and P.C.W. by Primate Conservation Inc. We thank Madagascar National Parks and the Malagasy Ministry of Environment for research permission, the Missouri Botanical Garden (MBG in St. Louis, MO) for access to herbarium collections, and the Parc Botanique et Zoologique de Tsimbazaza in Madagascar for help with species identification. We are grateful to M. Andriamalala, M. Rakotondrainibe, N. Beson, J.C. Ramanandraibe, P. Rasabo, J. Solo, G. Razafindrakoto, J. Mamiharilala, A. Pela, Marolahy, Leroa, Velomaro, Letsara, R. Solohely, P. Rafalinirina, S. Venkova, F. Ratelolahy and Ravalison for their valuable assistance in data collection and species identification, and to Dr Daniel Park for helpful discussion. O.H.R also thanks Harvard University for support during analysis and writing through the Sarah and Daniel Hrdy Fellowship in Conservation Biology.

\section{AUTHORS' CONTRIBUTIONS}

OHR and AED conceived the ideas and designed analyses; OHR, KAB, SEJ and PCW collected the data; OHR analysed the data with inputs from AED, KAB, SEJ and FC; OHR led the writing of the manuscript. All authors contributed critically to the drafts and gave final approval for publication.

This article is protected by copyright. All rights reserved. 


\section{DATA ACCESSIBILITY}

Data are available from the Dryad Digital Repository http://dx.doi.org/10.5061/dryad.jn743

(Razafindratsima et al. 2017).

\section{REFERENCES}

Asanok, L., Marod, D., Duengkae, P., Pranmongkol, U., Kurokawa, H., Aiba, M., Katabuchi, M. \& Nakashizuka, T. (2013) Relationships between functional traits and the ability of forest tree species to reestablish in secondary forest and enrichment plantations in the uplands of northern Thailand. Forest Ecology and Management, 296, 9-23.

Avise, J.C., Hubbell, S.P. \& Ayala, F.J. (2008) In the light of evolution II: Biodiversity and extinction. Proceedings of the National Academy of Sciences, 105, 11453-11457.

Benítez-Malvido, J., Gallardo-Vásquez, J.C., Alvarez-Añorve, M.Y. \& Avila-Cabadilla, L.D. (2014) Influence of matrix type on tree community assemblages along tropical dry forest edges. American Journal of Botany, 101, 820-829.

Brinck, K., Fischer, R., Groeneveld, J., Lehmann, S., De Paula, M.D., Pütz, S., Sexton, J.O., Song, D. \& Huth, A. (2017) High resolution analysis of tropical forest fragmentation and its impact on the global carbon cycle. Nature Communications, $\mathbf{8}, 14855$.

Brodie, J.F. \& Aslan, C.E. (2012) Halting regime shifts in floristically intact tropical forests deprived of their frugivores. Restoration Ecology, 20, 153-157.

Brown, K.A., Flynn, D.F.B., Abram, N.K., Ingram, J.C., Johnson, S.E. \& Wright, P. (2011) Assessing natural resource use by forest-reliant communities in Madagascar using functional diversity and functional redundancy metrics. PLoS ONE, 6, e24107.

Brown, K.A., Johnson, S.E., Parks, K.E., Holmes, S.M., Ivoandry, T., Abram, N.K., Delmore, K.E., Ludovic, R., Andriamaharoa, H.E., Wyman, T.M. \& Wright, P.C. (2013) Use of provisioning ecosystem services drives loss of functional traits across

This article is protected by copyright. All rights reserved. 
land use intensification gradients in tropical forests in Madagascar. Biological Conservation, 161, 118-127.

Cadotte, M.W., Cardinale, B.J. \& Oakley, T.H. (2008) Evolutionary history and the effect of biodiversity on plant productivity. Proceedings of the National Academy of Sciences of the United States of America, 105, 17012-17017.

Cadotte, M.W., Cavender-Bares, J., Tilman, D. \& Oakley, T.H. (2009) Using phylogenetic, functional and trait diversity to understand patterns of plant community productivity. PLoS ONE, 4, e5695.

Cavender-Bares, J., Kozak, K.H., Fine, P.V.A. \& Kembel, S.W. (2009) The merging of community ecology and phylogenetic biology. Ecology Letters, 12, 693-715.

Chaplin-Kramer, R., Ramler, I., Sharp, R., Haddad, N.M., Gerber, J.S., West, P.C., Mandle, L., Engstrom, P., Baccini, A., Sim, S., Mueller, C. \& King, H. (2015) Degradation in carbon stocks near tropical forest edges. Nature Communications, 6, 10158.

Chave, J., Andalo, C., Brown, S., Cairns, M.A., Chambers, J.Q., Eamus, D., Fölster, H., Fromard, F., Higuchi, N., Kira, T. \& others. (2005) Tree allometry and improved estimation of carbon stocks and balance in tropical forests. Oecologia, 145, 87-99.

Cornelissen, J.H.C., Lavorel, S., Garnier, E., Diaz, S., Buchmann, N., Gurvich, D.E., Reich, P.B., Ter Steege, H., Morgan, H.D., Van Der Heijden, M.G.A. \& others. (2003) A handbook of protocols for standardised and easy measurement of plant functional traits worldwide. Australian journal of Botany, 51, 335-380.

Ding, Y., Zang, R., Letcher, S.G., Liu, S. \& He, F. (2012) Disturbance regime changes the trait distribution, phylogenetic structure and community assembly of tropical rain forests. Oikos, 121, 1263-1270.

Díaz, S. \& Cabido, M. (2001) Vive la difference: plant functional diversity matters to ecosystem processes. Trends in ecology \& evolution, 16, 646-655.

This article is protected by copyright. All rights reserved. 
Dunham, A.E., Erhart, E.M. \& Wright, P.C. (2011) Global climate cycles and cyclones: consequences for rainfall patterns and lemur reproduction in southeastern Madagascar. Global Change Biology, 17, 219-227.

Flynn, D.F.B., Mirotchnick, N., Jain, M., Palmer, M.I. \& Naeem, S. (2011) Functional and phylogenetic diversity as predictors of biodiversity-ecosystem-function relationships. Ecology, 92, 1573-1581.

Gerhold, P., Cahill, J.F., Winter, M., Bartish, I.V. \& Prinzing, A. (2015) Phylogenetic patterns are not proxies of community assembly mechanisms (they are far better). Functional Ecology, 29, 600-614.

Giehl, E.L. \& Jarenkow, J.A. (2015) Disturbance and stress gradients result in distinct taxonomic, functional and phylogenetic diversity patterns in a subtropical riparian tree community. Journal of Vegetation Science, 26, 889-901.

Grime, J.P. (2006) Trait convergence and trait divergence in herbaceous plant communities: mechanisms and consequences. Journal of Vegetation Science, 17, 255-260.

Haddad, N.M., Brudvig, L.A., Clobert, J., Davies, K.F., Gonzalez, A., Holt, R.D., Lovejoy, T.E., Sexton, J.O., Austin, M.P., Collins, C.D., Cook, W.M., Damschen, E.I., Ewers, R.M., Foster, B.L., Jenkins, C.N., King, A.J., Laurance, W.F., Levey, D.J., Margules, C.R., Melbourne, B.A., Nicholls, A.O., Orrock, J.L., Song, D.-X. \& Townshend, J.R. (2015) Habitat fragmentation and its lasting impact on Earth's ecosystems. Science Advances, 1, e1500052.

Hill, M.O. (1973) Diversity and Evenness: A unifying notation and its consequences. Ecology, 54, 427-432.

Jost, L. (2006) Entropy and Diversity. Oikos, 113, 363-375.

This article is protected by copyright. All rights reserved. 
Kembel, S.W., Cowan, P.D., Helmus, M.R., Cornwell, W.K., Morlon, H., Ackerly, D.D., Blomberg, S.P. \& Webb, C.O. (2010) Picante: R tools for integrating phylogenies and ecology. Bioinformatics, 26, 1463-1464.

Kunstler, G., Lavergne, S., Courbaud, B., Thuiller, W., Vieilledent, G., Zimmermann, N.E., Kattge, J. \& Coomes, D.A. (2012) Competitive interactions between forest trees are driven by species' trait hierarchy, not phylogenetic or functional similarity: implications for forest community assembly. Ecology Letters, 15, 831-840.

Kurten, E.L., Wright, S.J. \& Carson, W.P. (2015) Hunting alters seedling functional trait composition in a Neotropical forest. Ecology, 96, 1923-1932.

Lasky, J.R., Sun, I., Su, S.-H., Chen, Z.-S., Keitt, T.H. \& others. (2013) Trait-mediated effects of environmental filtering on tree community dynamics. Journal of Ecology, 101, 722-733.

Laurance, W.F., Delamônica, P., Laurance, S.G., Vasconcelos, H.L. \& Lovejoy, T.E. (2000) Conservation: rainforest fragmentation kills big trees. Nature, 404, 836-836.

Laurance, W.F., Nascimento, H.E., Laurance, S.G., Andrade, A.C., Fearnside, P.M., Ribeiro, J.E. \& Capretz, R.L. (2006a) Rain forest fragmentation and the proliferation of successional trees. Ecology, 87, 469-482.

Laurance, W.F., Nascimento, H.E.M., Laurance, S.G., Andrade, A., Ribeiro, J.E.L.S., Pablo Giraldo, J., Lovejoy, T.E., Condit, R., Chave, J., Harms, K.E. \& D’Angelo, S. (2006b) Rapid decay of tree-community composition in Amazonian Forest Fragments. Proceedings of the National Academy of Sciences of the United States of America, 103, 19010-19014.

Letcher, S.G., Chazdon, R.L., Andrade, A.C.S., Bongers, F., van Breugel, M., Finegan, B., Laurance, S.G., Mesquita, R.C.G., Martínez-Ramos, M. \& Williamson, G.B. (2012) Phylogenetic community structure during succession: Evidence from three

This article is protected by copyright. All rights reserved. 
Neotropical forest sites. Perspectives in Plant Ecology, Evolution and Systematics, 14, $79-87$.

Lewis, S.L., Sonké, B., Sunderland, T., Begne, S.K., Lopez-Gonzalez, G., Van Der Heijden, G.M., Phillips, O.L., Affum-Baffoe, K., Baker, T.R., Banin, L. \& others. (2013) Above-ground biomass and structure of 260 African tropical forests. Philosophical Transactions of the Royal Society B: Biological Sciences, 368, 20120295.

Magnago, L.F.S., Magrach, A., Barlow, J., Schaefer, C.E.G.R., Laurance, W.F., Martins, S.V. \& Edwards, D.P. (2017) Do fragment size and edge effects predict carbon stocks in trees and lianas in tropical forests? Functional Ecology, 31, 542-552.

Marini, L., Bruun, H.H., Heikkinen, R.K., Helm, A., Honnay, O., Krauss, J., Kühn, I., Lindborg, R., Pärtel, M. \& Bommarco, R. (2012) Traits related to species persistence and dispersal explain changes in plant communities subjected to habitat loss. Diversity and Distributions, 18, 898-908.

Mason, N.W.H., Irz, P., Lanoiselée, C., Mouillot, D. \& Argillier, C. (2008) Evidence that niche specialization explains species-energy relationships in lake fish communities. Journal of Animal Ecology, 77, 285-296.

Mayfield, M.M. \& Levine, J.M. (2010) Opposing effects of competitive exclusion on the phylogenetic structure of communities. Ecology Letters, 13, 1085-1093.

Murcia, C. (1995) Edge effects in fragmented forests: implications for conservation. Trends in ecology \& evolution, 10, 58-62.

Nathan, R. \& Muller-Landau, H.C. (2000) Spatial patterns of seed dispersal, their determinants and consequences for recruitment. Trends in Ecology \& Evolution, 15, $278-285$.

This article is protected by copyright. All rights reserved. 
Norden, N., Letcher, S.G., Boukili, V., Swenson, N.G. \& Chazdon, R. (2012) Demographic drivers of successional changes in phylogenetic structure across life-history stages in plant communities. Ecology, 93, 70-82.

Osuri, A.M., Ratnam, J., Varma, V., Alvarez-Loayza, P., Hurtado Astaiza, J., Bradford, M., Fletcher, C., Ndoundou-Hockemba, M., Jansen, P.A., Kenfack, D., Marshall, A.R., Ramesh, B.R., Rovero, F. \& Sankaran, M. (2016) Contrasting effects of defaunation on aboveground carbon storage across the global tropics. Nature Communications, $\mathbf{7}$, 11351.

Osuri, A.M. \& Sankaran, M. (2016) Seed size predicts community composition and carbon storage potential of tree communities in rain forest fragments in India's Western Ghats. Journal of Applied Ecology, 53, 837-845.

Pagel, M. (1999) Inferring the historical patterns of biological evolution. Nature, 401, 877884.

Peres, C.A., Emilio, T., Schietti, J., Desmoulière, S.J.M. \& Levi, T. (2016) Dispersal limitation induces long-term biomass collapse in overhunted Amazonian forests. Proceedings of the National Academy of Sciences, 113, 892-897.

Petchey, O.L. \& Gaston, K.J. (2002) Functional diversity (FD), species richness and community composition. Ecology Letters, 5, 402-411.

Poulsen, J.R., Clark, C.J. \& Palmer, T.M. (2013) Ecological erosion of an Afrotropical forest and potential consequences for tree recruitment and forest biomass. Biological Conservation, 163, 122-130.

R Core Team. (2016) R: A Language and Environment for Statistical Computing. R Foundation for Statistical Computing, Vienna, Austria.

This article is protected by copyright. All rights reserved. 
Razafindratsima, O.H., Brown, K.A., Carvalho, F., Johnson, S.E., Wright, P.C. \& Dunham, A.E. (2017) Data from: Edge effects on components of diversity and above-ground biomass in a tropical rainforest. Dryad Data Repository., 10.5061/dryad.jn743.

Razafindratsima, O.H. \& Dunham, A.E. (2015) Assessing the impacts of nonrandom seed dispersal by multiple frugivore partners on plant recruitment. Ecology, 96, 24-30.

Razafindratsima, O.H. \& Dunham, A.E. (2016a) Co-fruiting plant species share similar fruit and seed traits while phylogenetic patterns vary through time. Journal of Ecology, 104, 1789-1798.

Razafindratsima, O.H. \& Dunham, A.E. (2016b) Frugivores bias seed-adult tree associations through non-random seed dispersal: a phylogenetic approach. Ecology, 97, 20942102.

Razafindratsima, O.H. \& Dunham, A.E. (2016c) Data from: Co-fruiting plant species share similar fruit and seed traits while phylogenetic patterns vary through time. Dryad Data Repository, doi: 10.5061/dryad.g4n11.

Razafindratsima, O.H., Jones, T.A. \& Dunham, A.E. (2014) Patterns of movement and seed dispersal by three lemur species. American Journal of Primatology, 76, 84-96.

Razafindratsima, O.H., Mehtani, S. \& Dunham, A.E. (2013) Extinctions, traits and phylogenetic community structure: insights from primate assemblages in Madagascar. Ecography, 36, 47-56.

Santos, B.A., Arroyo-Rodríguez, V., Moreno, C.E. \& Tabarelli, M. (2010) Edge-related loss of tree phylogenetic diversity in the severely fragmented Brazilian Atlantic forest. PLoS ONE, 5, e12625.

Schatz, G.E. (2001) Generic Tree Flora of Madagascar. Royal Botanical Gardens, Kew \& Missouri Botanical Gardens, Great Britain.

This article is protected by copyright. All rights reserved. 
Schupp, E.W. (1995) Seed-seedling conflicts, habitat choice, and patterns of plant recruitment. American Journal of Botany, 82, 399-409.

Slik, J.W.F. (2005) Assessing tropical lowland forest disturbance using plant morphological and ecological attributes. Forest Ecology and Management, 205, 241-250.

Stournaras, K.E., Lo, E., Böhning-Gaese, K., Cazetta, E., Matthias Dehling, D., Schleuning, M., Stoddard, M.C., Donoghue, M.J., Prum, R.O. \& Martin Schaefer, H. (2013) How colorful are fruits? Limited color diversity in fleshy fruits on local and global scales. New Phytologist, 198, 617-629.

Swenson, N.G. \& Enquist, B.J. (2009) Opposing Assembly Mechanisms in a Neotropical Dry Forest: Implications for Phylogenetic and Functional Community Ecology. Ecology, 90, 2161-2170.

Sydenham, M.A.K., Moe, S.R., Totland, Ø. \& Eldegard, K. (2015) Does multi-level environmental filtering determine the functional and phylogenetic composition of wild bee species assemblages? Ecography, 38, 140-153.

Turk, D. (1995) A Guide to Trees of Ranomafana National Park and Central Eastern Madagascar. US Agency for International Development, Washington DC.

Van der Plas, F., Anderson, T.M. \& Olff, H. (2012) Trait similarity patterns within grass and grasshopper communities: multitrophic community assembly at work. Ecology, 93, 836-846.

Webb, C.O. (2000) Exploring the phylogenetic structure of ecological communities: an example for rain forest trees. The American Naturalist, 156, 145-155.

Webb, C.O., Ackerly, D.D., McPeek, M.A. \& Donoghue, M.J. (2002) Phylogenies and community ecology. Annual Review of Ecology and Systematics, 33, 475-505.

Webb, C.O. \& Donoghue, M.J. (2005) Phylomatic: tree assembly for applied phylogenetics. Molecular Ecology Notes, 5, 181-183.

This article is protected by copyright. All rights reserved. 
Westoby, M., Falster, D.S., Moles, A.T., Vesk, P.A. \& Wright, I.J. (2002) Plant ecological strategies: some leading dimensions of variation between species. Annual review of ecology and systematics, 33, 125-159.

Wright, P.C. \& Andriamihaja, B. (2002) Making a rain forest national park work in Madagascar: Ranomafana National Park and its long-term research commitment. Making parks work: strategies for preserving tropical nature (eds J. Terborgh, C.P. van Schaik, L. Davenport, \& R. Madhu), pp. 112-136. Island Press, Washington, DC.

Zanne, A.E., Tank, D.C., Cornwell, W.K., Eastman, J.M., Smith, S.A., FitzJohn, R.G., McGlinn, D.J., O’Meara, B.C., Moles, A.T., Reich, P.B., Royer, D.L., Soltis, D.E., Stevens, P.F., Westoby, M., Wright, I.J., Aarssen, L., Bertin, R.I., Calaminus, A., Govaerts, R., Hemmings, F., Leishman, M.R., Oleksyn, J., Soltis, P.S., Swenson, N.G., Warman, L. \& Beaulieu, J.M. (2014) Three keys to the radiation of angiosperms into freezing environments. Nature, 506, 89-92.

Zhu, J., Jiang, L. \& Zhang, Y. (2016) Relationships between functional diversity and aboveground biomass production in the Northern Tibetan alpine grasslands. Scientific Reports, 6, srep34105.

\section{DATA SOURCES}

Chave, J., Coomes, D., Jansen, S., Lewis, S.L., Swenson, N.G. \& Zanne, A.E. (2009) Towards a worldwide wood economics spectrum. Ecology letters, 12, 351-366.

Dew, J.L. \& Wright, P. (1998) Frugivory and seed dispersal by four species of primates in Madagascar's eastern rain forest. Biotropica, 30, 425-437.

Hemingway, C.A. (1996) Morphology and phenology of seeds and whole fruit eaten by Milne-Edwards' sifaka, Propithecus diadema edwardsi, in Ranomafana National Park, Madagascar. International journal of primatology, 17, 637-659.

This article is protected by copyright. All rights reserved. 
Overdorff, D.J. (1993) Similarities, differences, and seasonal patterns in the diets of Eulemur rubriventer and Eulemur fulvus rufus in the Ranomafana National Park, Madagascar. International Journal of Primatology, 14, 721-753.

Razafindratsima, O.H. \& Dunham, A.E. (2016a) Frugivores bias seed-adult tree associations through non-random seed dispersal: a phylogenetic approach. Ecology, 97, 20942102.

Razafindratsima, O.H. \& Dunham, A.E. (2016b) Data from: Co-fruiting plant species share similar fruit and seed traits while phylogenetic patterns vary through time. Dryad Data Repository, doi: 10.5061/dryad.g4n11.

Razafindratsima, O.H. \& Dunham, A.E. (2016c) Co-fruiting plant species share similar fruit and seed traits while phylogenetic patterns vary through time. Journal of Ecology, 104, 1789-1798.

Razafindratsima, O.H., Jones, T.A. \& Dunham, A.E. (2014) Patterns of movement and seed dispersal by three lemur species. American Journal of Primatology, 76, 84-96.

White, F.J., Overdorff, D.J., Balko, E.A. \& Wright, P.C. (1995) Distribution of ruffed lemurs (Varecia variegata) in Ranomafana National Park, Madagascar. Folia Primatologica, 64, 124-131.

Zanne, A.E., Lopez-Gonzalez, G., Coomes, D.A., Ilic, J., Jansen, S., Lewis, S.L., Miller, R.B., Swenson, N.G., Wiemann, M.C. \& Chave, J. (2009) Data from: Towards a worldwide wood economics spectrum. Dryad Digital Repository. http://dx.doi.org/10.5061/dryad.234

This article is protected by copyright. All rights reserved. 


\section{TABLES}

Table 1. Traits used to measure tree functional diversity.

\begin{tabular}{|c|c|}
\hline Trait & Ranges, categories \\
\hline \multicolumn{2}{|l|}{ Dispersal traits: } \\
\hline Dispersal mode & abiotic, bird, lemur, both bird and lemur \\
\hline Fruit color & $\begin{array}{l}\text { red, yellow red, orange, black, brown, yellow, green yellow, } \\
\text { green, blue, purple, red purple }\end{array}$ \\
\hline Fruit length & $1-194.70 \mathrm{~mm}$ \\
\hline Fruit width & $1-64.54 \mathrm{~mm}$ \\
\hline Seed size & small: $<5 \mathrm{~mm}$, medium: 5-10 mm, large: $>10 \mathrm{~mm}$ \\
\hline \multicolumn{2}{|l|}{ Productivity traits: } \\
\hline Plant height & $5.45-25 \mathrm{~m}$ \\
\hline Leaf area & $133.96-608597.2 \mathrm{~mm}^{2}$ \\
\hline Wood density & $0.08-1.62 \mathrm{~g} / \mathrm{cm}^{3}$ \\
\hline Spinescence & with or without spines \\
\hline Growth rate & slow, fast \\
\hline Longevity & $<25,25-50,>50$ years \\
\hline
\end{tabular}

\section{FIGURE CAPTIONS}

Figure 1. Ordination of tree communities in forest edge and interior habitats in terms of species composition, as represented by two axes of nonmetric multidimensional scaling (NMDS). Each point corresponds to a plot numbered 1 to $7 ; \mathrm{E}=$ edge habitats, $\mathrm{I}=$ interior habitats.

Figure 2. Variation in the values of $M P D, F D$ (for dispersal and productivity traits) and total above-ground biomass between tree communities in forest edge $v s$. interior habitats. $P$ and $t$ values above each graph correspond to the results of Linear Mixed-Effects models comparing the observed values of each metric between tree communities in forest edge $v s$. interior habitats. Dots represent the value of each metric for each plot (black: edge, white: interior), and the dashed lines link the paired plots in the same site.

Figure 3. Index of variance $(I V)$ values for the functional diversity index for dispersal- and

This article is protected by copyright. All rights reserved. 
productivity-related traits $v s$. species richness for tree communities in forest edge (black dots) and in interior habitat (white dots). A positive $I V$ value indicates that the observed value of trait divergence is greater than expected at random. Mean values of IV.FD and Species Richness across communities in edge and interior habitats are represented by the diamonds with standard error bars.

\section{SUPPORTING INFORMATION}

Additional Supporting Information may be found in the online version of this article:

Figure S1. Map showing the location of the plots. Inset: Map of Madagascar showing forest cover (in green) and the location of Ranomafana National Park (in red)

Appendix S1. Species composition of the tree communities

Appendix S2. Newick file of our regional phylogenetic tree

Appendix S3. Detailed description of the sampling and measurement methodologies

Appendix S4. Phylogenetic signal in each trait

Appendix S5. Results of other allometric models for calculating AGB

Appendix S6. Distribution of each of the three traits used in estimating above-ground biomass

Appendix S7. Forest structure in edge and interior habitats

This article is protected by copyright. All rights reserved. 


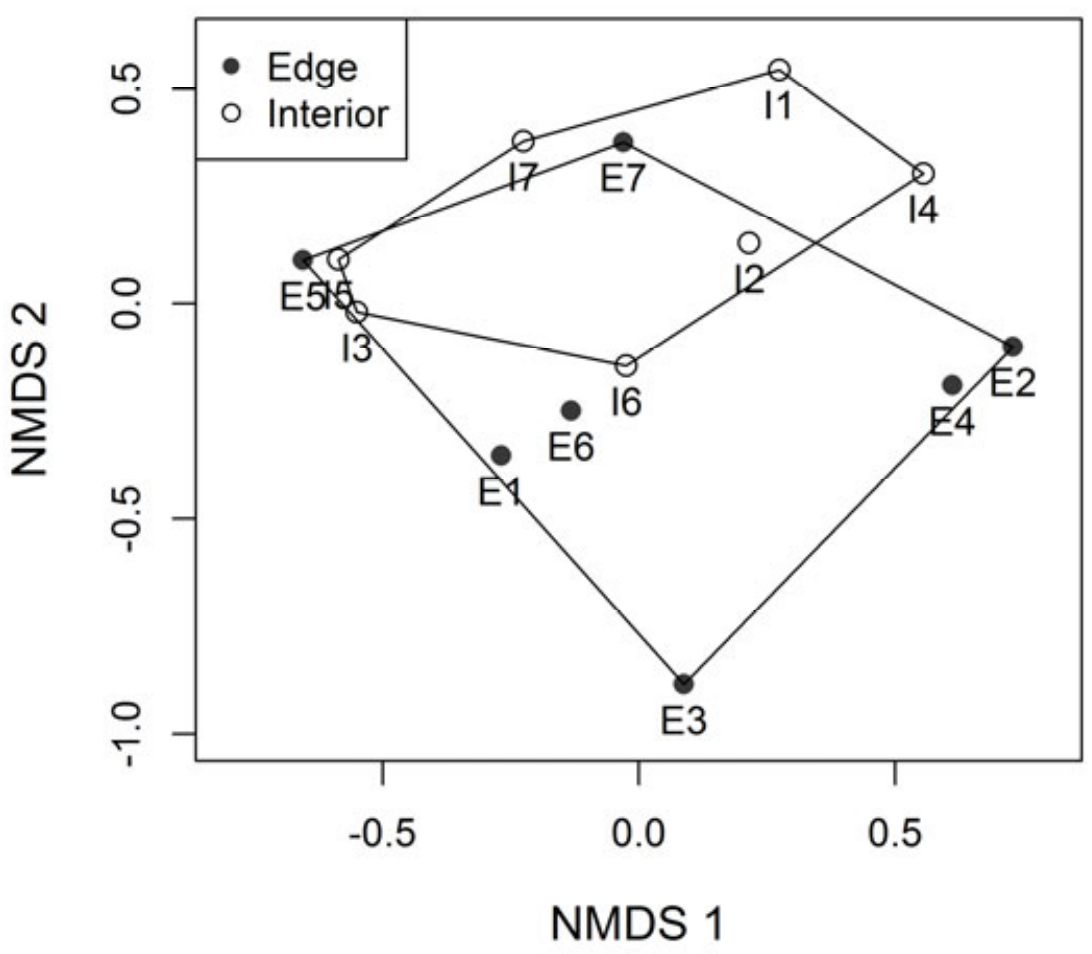

This article is protected by copyright. All rights reserved. 

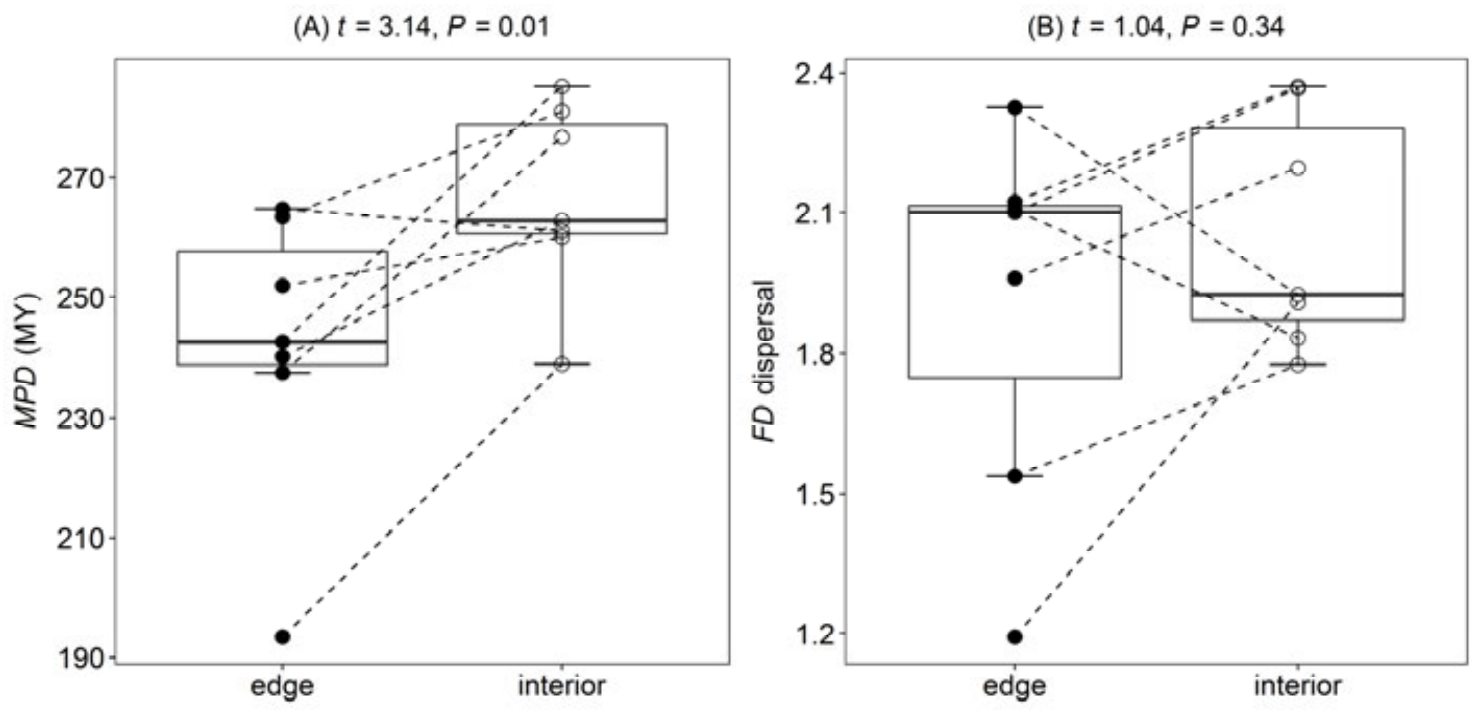

(C) $t=4.19, P=0.01$
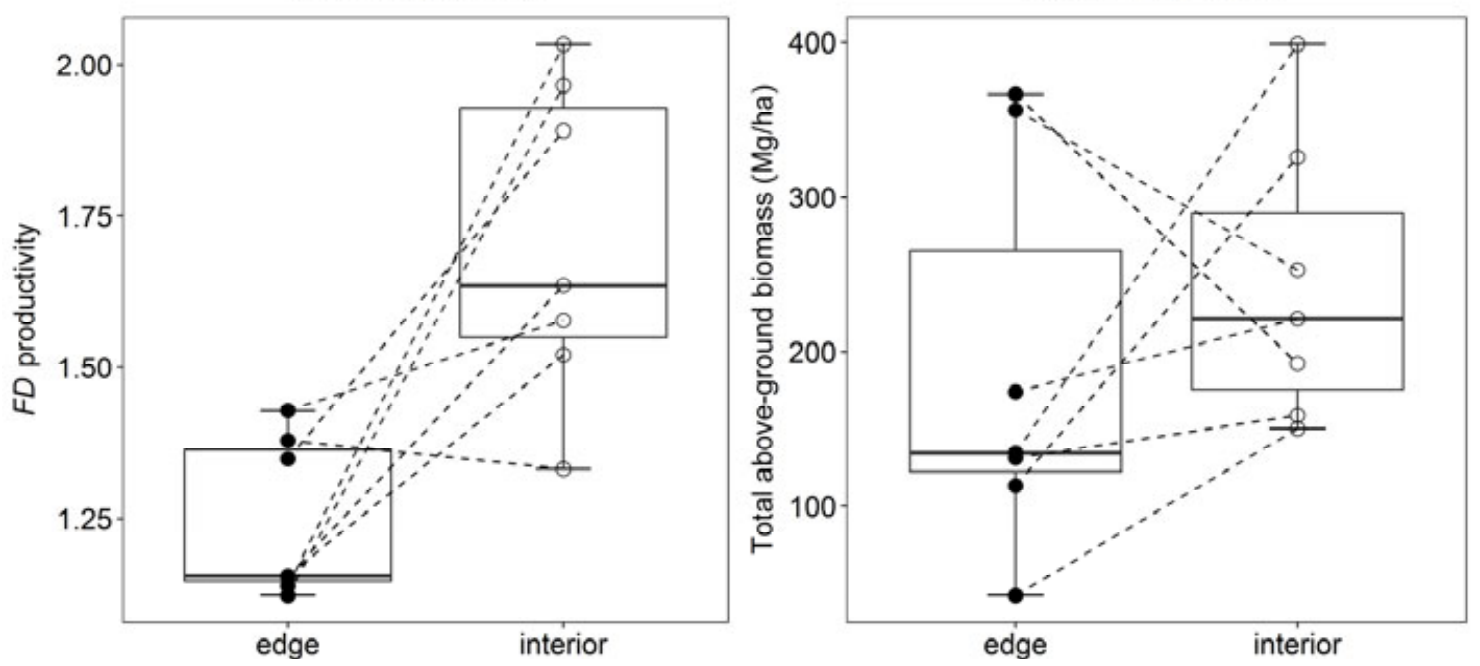

This article is protected by copyright. All rights reserved. 

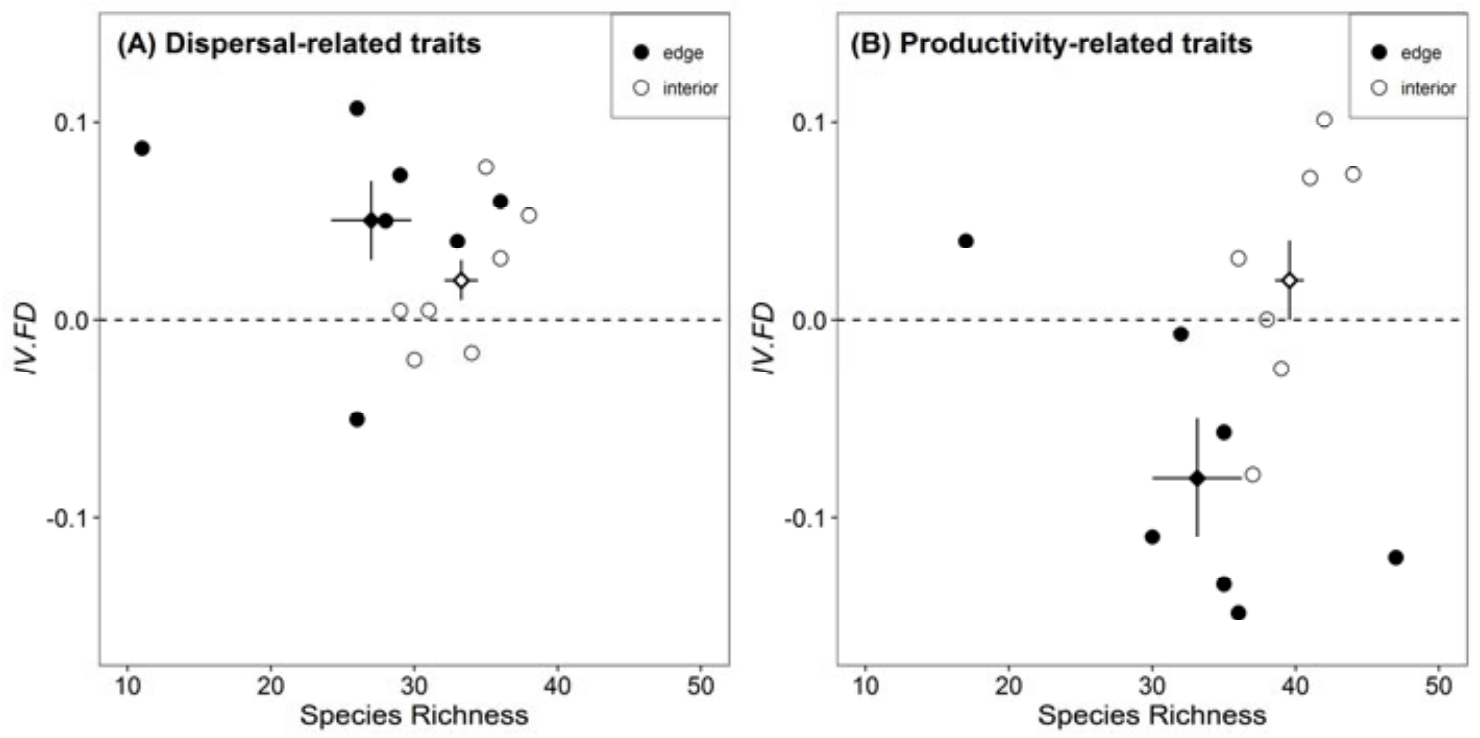

This article is protected by copyright. All rights reserved. 